\title{
The ADMIT series - Issues in Inhalation Therapy. 2) Improving technique and clinical effectiveness
}

\section{*Mariëlle EAC Broeders ${ }^{a}$, Joaquin Sanchis ${ }^{b}$, Mark L Levyc, Graham K Cromptond, PN Richard Dekhuijzena, on behalf of the ADMIT Working Groupe}

a Dept. of Pulmonary Diseases, Radboud University Nijmegen Medical Centre, The Netherlands

${ }^{\text {b }}$ Departament de Pneumologia, Hospital de la Santa, Santa Creu i Sant Pau, Universitat Autónoma de Barcelona, Spain

c Senior Clinical Research Fellow, Allergy \& Respiratory Research Group, Division of Community Health Sciences:GP Section, University of Edinburgh, Scotland, UK

'Western General Hospital, Edinburgh, UK

e Members of the Aerosol Drug Management Improvement Team (ADMIT): Peter J Barnes, London, UK; Mariëlle Broeders, Nijmegen, The Netherlands; Chris Corrigan, London, UK; Graham K Crompton, Edinburgh, UK; Lorenzo Corbetta, Firenze, Italy; Richard Dekhuijzen, Nijmegen, The Netherlands; Jean Christophe Dubus, Marseille, France; Thomas Hausen, Essen, Germany; Meinhard Kneussl, Vienna, Austria; Federico Lavorini, Firenze, Italy; Mark L Levy, Edinburgh, UK; Soren Pedersen, Kolding, Denmark; Antonio Ramalho de Almeida, Porto, Portugal; Joaquin Sanchis, Barcelona, Spain; Jose L. Viejo, Hospital General Yagüe de Burgos, Spain; Walter Vincken, Brussels, Belgium; Thomas Voshaar, Moers, Germany

Received 26th February 2008; resubmitted 29th September 2008; accepted 6th February 2009; online 19th May 2009

\begin{abstract}
Aerosol inhalation is considered the optimal route for administering the majority of drugs for the treatment of obstructive airways diseases. A number of Pressurised Metered-Dose and Dry Powder Inhalers are available for this purpose. However, inhalation of therapeutic aerosols is not without difficulty; it requires precise instructions on the inhalation manoeuvre, which is different from spontaneous normal breathing Also, the characteristics of the inhaler device have to be suitable for the user. Available data indicate a frequent lack of knowledge demonstrated by health professionals and patients on the inhalation manoeuvre and handling of inhalers, resulting in a reduction of therapeutic benefit. This paper reviews the literature concerning the fundamental aspects of inhaler devices, inhalation manoeuvre and device selection, in an attempt to increase the knowledge of, and to optimise the clinical use of, therapeutic inhalers.

(C) 2009 General Practice Airways Group. All rights reserved.

MEAC Broeders et al. Prim Care Resp J 2009; 18(2): 76-82.

doi:10.4104/pcrj.2009.00025
\end{abstract}

Keywords inhalers, inhalation technique, aerosol therapy, pMDI, dry powder inhalers

\section{Contents}

Abstract

Introduction

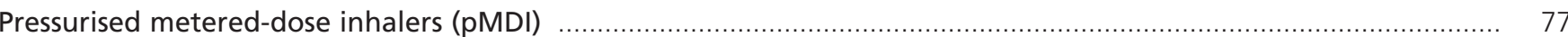

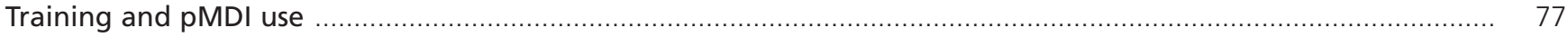

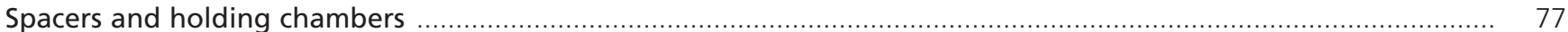

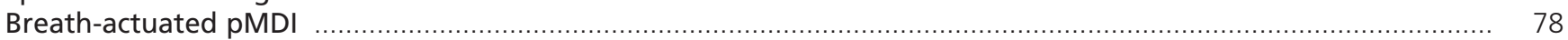

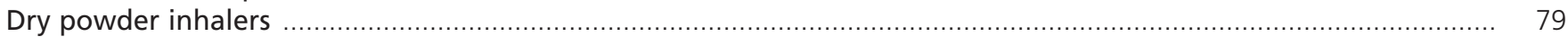

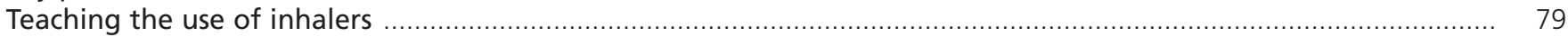

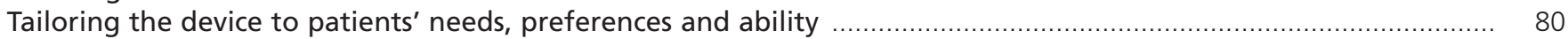

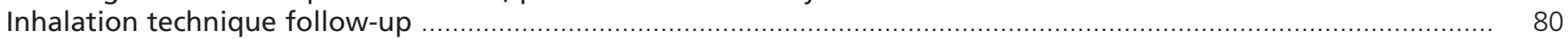

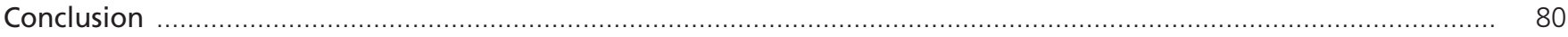

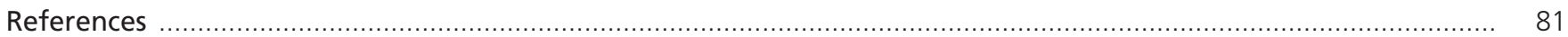

* Corresponding author: Dr Marielle EAC Broeders, Dept. of Pulmonary Diseases - 454, Radboud University Nijmegen Medical Centre, P.O. Box 9101, 6500 HB Nijmegen, The Netherlands. Tel +31-24-3614579 Fax +31-24-3610324 E-mail: m.broeders@long.umcn.nl 


\section{Introduction}

Aerosol inhalation is considered the optimal route of administering the majority of drugs for the treatment of obstructive airway diseases. The major and most important advantage of inhaled therapy is that drugs are delivered directly into the airways, producing higher local concentrations for better efficacy and with significantly less systemic exposure with less risk of systemic side effects. ${ }^{1-3}$ For this, a number of different inhalation devices are available. The pressurised metered-dose inhaler (pMDI) is presently the most commonly used. Alternatively, drugs can be administered by dry powder inhalers (DPI) or nebulisers. Since inhalation therapy will probably remain the cornerstone of asthma and chronic obstructive pulmonary disease (COPD) treatment for the foreseeable future, it is important to provide helpful information that may assist physicians and nurses to select appropriate devices for individual patients. This paper is the second in a series of reviews on various inhalation therapy topics being published in this journal by the ADMIT working group (see Addendum for affiliations and see the first review paper $^{4}$ for individual conflict of interest declarations). The first paper focused on asthma control, its components, and the limiting influences on patients' achievement of asthma control. ${ }^{4}$

Most studies on inhalation technique have been performed in patients with asthma, ${ }^{5}$ and less is known of COPD patients. ${ }^{6-8}$ However, in our opinion the fundamental aspects related to inhaler devices, their prescribing, and the inhalation technique required, apply to both groups of patients. One of the forthcoming papers in the ADMIT series will address inhalation issues specifically in COPD patients, and another will deal with nebulisers.

Information on the characteristics and performance of different inhalers has been reviewed previously. ${ }^{9,10}$ There is a need to increase knowledge and optimise clinical use of therapeutic aerosols. This paper is an overview of the key requirements for the successful use of current pMDI and DPI inhalers, both from the point of view of manipulation of the devices and the necessary inhalation manoeuvres. Furthermore, key characteristics and peculiarities of the most commonly used inhalers, and critical aspects of their use which are essential for efficient drug delivery, are discussed.

\section{Pressurised metered-dose inhalers (pMDIs)}

In some countries cost considerations dictate the high prescribing of pMDIs, despite the fact that many adults and children have difficulty using them. ${ }^{11,12}$ Inefficient inhalation technique is a common problem, resulting in poor drug delivery and reduced disease control. ${ }^{13}$ Assessment of pMDI use in 1173 outpatients attending a respiratory clinic showed that $51 \%$ of them had serious problems co-ordinating actuation with inspiration, $24 \%$ of these patients stopped inhaling prematurely after actuation, and in $12 \%$ the aerosol was released into the mouth while inhaling through the nose. ${ }^{11}$ Between 8 and $59 \%$ of pMDI users have poor or inadequate inhalation technique, ${ }^{5}$ the main problem being difficulty in co-ordinating pMDI actuation with inspiration. ${ }^{5,11}$ Inhaler technique in patients using the pMDI is further complicated by the exit velocity and evaporation temperature of aerosol propellants (freons). The sudden impact of cold freon onto the oropharynx can lead to a reflex arrest of inspiration ('the cold freon effect') or continuation of inspiration through the nose instead of the mouth. ${ }^{11}$ This problem may be less marked with the new hydrofluoroalkane (HFA) propellant-driven pMDIs due to their slower speed of delivery. ${ }^{14}$

\section{Training and pMDI use}

The importance of training patients how to use a pMDI was emphasised by Orehek et al. ${ }^{15}$ and Paterson and Crompton ${ }^{16}$ as early as 1976. They concluded that the majority of asthmatics probably derive incomplete benefit from the use of pMDIs. A few years later, Gayrard and Orehek ${ }^{17}$ reported that only $28 \%$ of an untrained group of asthma patients demonstrated correct use of the pMDI compared to $52 \%$ in the case of a trained group. Lenney et al, ${ }^{18}$ in a study of 100 adults naïve to inhaler devices and tested for their ability to use six different inhalers, found that only $21 \%$ could use the pMDI efficiently after reading and assimilating the manufacturers' package insert, and only 52\% could do so after expert tuition. The problem is compounded by the fact that with time many patients lose the ability to use a pMDI correctly. 5,11 Hence, a pMDI should only be prescribed for patients who have demonstrated they can use it correctly. Furthermore, the patient's inhalation technique should be checked regularly during follow-up. There are a number of devices available for training health professionals as well as patients in the use of inhalers, such as the 2Tone (Canday Medical Ltd), Vitalograph AIMS Machine (Vitalograph, UK) and In-Check Dial (Clement Clarke Ltd, UK). A list of the advantages and disadvantages of pMDIs is presented in Table 1 and essential features of the correct usage of these are summarised in Table 2.

\section{Spacers and holding chambers}

Spacer devices or holding chambers (i.e. a spacer with a oneway inspiratory valve) placed between the actuator and the mouth are used to reduce the problems of co-ordinating actuation and inhalation with pMDIs, as well as oropharyngeal impact. Impaction of larger particles on the wall of the device prior to inhalation and size reduction by evaporation of droplets initially unsuitable for inhalation, optimises the aerosol particle size whilst reducing side-effects 
MEAC Broeders et al.

Table 1. Advantages and disadvantages of pMDI and DPI.

\begin{tabular}{|c|c|c|}
\hline Type & Advantages & Disadvantages \\
\hline $\begin{array}{l}\text { pMDI (pressurised } \\
\text { metered dose inhaler) }\end{array}$ & $\begin{array}{l}\text { Portable and compact } \\
\text { Difficult to contaminate } \\
\text { Less expensive than most other inhalers } \\
\text { Dose delivered and particle size independent of } \\
\text { inhalation manoeuvre } \\
\text { Suitable for emergency situations } \\
\text { Short treatment time } \\
\text { Available for most inhaled drug formulations }\end{array}$ & $\begin{array}{l}\text { Requires co-ordination of inspiration and actuation } \\
\text { High oropharyngeal deposition (without spacer) } \\
\text { Not suited for children < } 6 \text { years (without spacer) } \\
\text { No dose counter to assess remaining doses } \\
\text { Propellant required } \\
\text { Sensitive to low ambient temperature }\end{array}$ \\
\hline pMDI + Spacer & $\begin{array}{l}\text { Suitable for small children and impaired adults } \\
\text { Reduction of oropharyngeal deposition } \\
\text { Suitable for emergency situations }\end{array}$ & $\begin{array}{l}\text { Delay, multiple puffs and static charge reduce lung } \\
\text { bioavailability } \\
\text { Bulky; much less portable than pMDI alone } \\
\text { Most spacers are specifically designed for a given pMDI }\end{array}$ \\
\hline Breath actuated pMDI & $\begin{array}{l}\text { Overcomes co-ordination problems } \\
\text { Short treatment time }\end{array}$ & $\begin{array}{l}\text { Induces interruption of inhalation in some (cold freon effect) } \\
\text { More bulky and noisy than conventional pMDI } \\
\text { Requires a higher inspiratory flow to be triggered }\end{array}$ \\
\hline DPI (dry powder inhalers) & $\begin{array}{l}\text { Small and portable } \\
\text { Breath actuated } \\
\text { Less patient co-ordination required } \\
\text { Short treatment time } \\
\text { Available for most substances }\end{array}$ & $\begin{array}{l}\text { Moderate to high inspiratory flow required } \\
\text { Not suited for children }<4 \mathrm{yr} \\
\text { May not be appropriate for emergency situations } \\
\text { Some sensitive to humidity } \\
\text { Not suitable for delivering large doses of bronchodilators }\end{array}$ \\
\hline
\end{tabular}

\section{Table 2. Correct technique for using a pMDI (*).}

1) Take the cap off the inhaler mouthpiece.

2) Shake the inhaler.

3) Hold the inhaler upright.

4) Breathe out.

5) Place the inhaler mouthpiece between the lips (and the teeth); keep the tongue from obstructing the mouthpiece.

6) Trigger the inhaler while breathing in deeply and slowly (this should be at about $30 \mathrm{l} / \mathrm{min}$ ).

7) Continue to inhale until the lungs are full.

8) Hold the breath while counting to 10.

9) Breathe out slowly.

$\left.{ }^{*}\right)$ Modified from ref. 47

related to oropharyngeal deposition and gut absorption. ${ }^{19}$ The net result of adding a large volume holding chamber will depend upon the relative effects of the chamber on lung and gut bioavailability of the drug, as reviewed by Lipworth. ${ }^{20}$ Lung aerosol deposition and availability may also differ when a given holding chamber is used with either a CFC- or an HFA-propelled pMDI. ${ }^{21}$ Holding chambers don't prevent inconsistent medication delivery caused by electrostatic charge of the aerosol, incorrect operation or patient specific factors. ${ }^{22}$

There are a large number of different commercially available spacer-pMDI combinations and each have their own
Table 3. Correct technique for using pMDI + spacer (inhalation chamber).

1) Take the cap off the inhaler mouthpiece.

2) Shake the inhaler.

3) Connect pMDI mouthpiece to the back of the spacer.

4) Put spacer's mouthpiece between your teeth and close the lips around it.

5) Actuate canister once, inhale slowly and deeply 3-5 times.

performance characteristics. Some spacers (for example the Aerochamber ${ }^{\circledast}$ ) are not inhaler-specific, and are designed to allow connection with any pMDI, and some have a facemask, helpful in delivery of drug in children. Low volume spacers can reduce the respirable dose by $60 \%$ and offer less protection against poor co-ordination. ${ }^{23}$ Therefore, a spacer device with a volume of over $100 \mathrm{ml}$ is preferable.

Bronchodilatory therapy via nebulisation or pMDI plus spacer is recommended for the management of exacerbations of asthma and COPD as per Global Initiative on Asthma (GINA) ${ }^{24}$ and Global Initiative on Chronic Obstructive Lung Disease (GOLD) ${ }^{25}$ guidelines. Studies suggest that they are equally effective. ${ }^{10}$

Essential features of the correct usage of the pMDI with a spacer are summarised in Table 3.

\section{Breath-actuated pMDIs}

Breath-actuated pMDIs are alternatives to pMDIs used with or without a spacer. These devices contain a conventional 


\section{Table 4. Correct technique for using breath-actuated} pMDI.

1) Take the cap off the inhaler mouthpiece (Autohaler).

2) Cock the lever at the top (Autohaler).

3) Shake the inhaler.

4) Hold the inhaler upright.

5) Breathe out.

6) Place the inhaler mouthpiece between the lips (and the teeth); keep the tongue from obstructing the mouthpiece.

7) Breathe in deeply and slowly without stopping.

8) Continue to inhale until the lungs are full.

9) Hold the breath while counting to 10

10) Breathe out slowly.

pressurised canister and have a flow-triggered system driven by a spring which releases the dose during inhalation (for example the Autohaler ${ }^{\circledast}$ ). A study investigating the breathactuated pMDI found no significant difference in lung deposition between 'good' and 'bad' users. ${ }^{26}$ In both groups of subjects, deposition was close to that achieved by optimal pMDI users, optimal use being based on appropriate coordination between deep inspiration and puff release and post-inspiration breath-holding of a few seconds. ${ }^{26}$ However, breath-actuated devices (and some DPIs) have the disadvantage of requiring a relatively higher inspiratory flow of approximately $30 \mathrm{~L} / \mathrm{min}$ for triggering drug release - when they generate a "click", 27 thus providing some auditory feedback of device actuation. As in the case of pMDIs, breathactuated pMDIs are also prone to inducing the "cold freon effect" which may interrupt inhalation as the cold blast of medication hits the back of the pharynx. This limitation might be improved by the new Autohaler ${ }^{\otimes}$ propelled with hydrofluoroalkane-134a instead of CFC. ${ }^{28}$ The correct use of breath-actuated devices is summarised in Table 4.

\section{Dry powder inhalers}

The first DPI, the Spinhaler, was introduced into clinical practice in the early 1970s, exclusively for use with disodium cromoglicate..$^{29}$ In 1977, a single dose DPI (Rotahaler) was introduced for use with salbutamol, and for use with beclometasone dipropionate in the following year. ${ }^{30}$ The Turbuhaler $^{31}$ and Diskhaler ${ }^{32}$ were the first multi-dose DPIs available for clinical practice, followed some years later by the Diskus/Accuhaler. ${ }^{33}$ Following the clinical success of the DPI, several gravity-fed reservoir inhalers have been produced. DPI advantages and disadvantages are summarised in Table 1. DPIs are actuated and driven by inspiratory flow, as are breath-actuated pMDIs. Consequently, DPIs and breathactuated pMDIs require less co-ordination between inspiration and firing of the device for drug delivery as compared to

\section{Table 5. Correct technique for the DPI $(*)$.}

1) Remove mouthpiece cover

2) Sit upright or stand

3) Exhale deeply, away from the mouthpiece

4) Put mouthpiece between teeth and close lips around

5) Inhale deeply and forcefully

6) Remove Inhaler from the mouth

7) Hold breath for 10 seconds

8) Breathe out slowly

$\left.{ }^{*}\right)$ Modified from ref. 7 and 18

pMDIs. As opposed to the manoeuvres required with a pMDI, an initially high inspiratory flow is needed to disaggregate the drug powder in the DPI into respirable particles. A forceful inhalation through the inhaler will result in better disaggregation, finer particles, and consequently greater transfer of respirable drug particles to the airways. ${ }^{34}$ Thus, to achieve a high lung deposition of drug from a DPI, a 'deep and forceful' inspiration with a very rapid onset should ideally be performed; this seems to be attainable by most patients ${ }^{33,34}$ (see Table 5). The need for an initially high inspiratory flow varies for the different devices. ${ }^{35}$

Since exacerbations of asthma and COPD are associated with considerable airflow limitation and respiratory muscle fatigue, some studies have investigated the efficacy of the use of DPIs in the acute setting. Brown et al. concluded that $98 \%$ of 99 acute asthma patients could generate sufficient inspiratory flow (peak inspiratory flow $>30 \mathrm{~L} / \mathrm{min}$ ) through the Turbuhaler. ${ }^{36}$ Nevertheless, international guidelines suggest the use of nebulisers or a pMDI plus spacer in the acute setting..$^{24,25}$

High ambient air humidity hinders disaggregation and this can result in impairment of drug delivery ${ }^{37}$ - hence the importance of adherence to the manufacturer's advice on storage and manipulation of the inhaler.

In "real life" studies on pMDIs and DPIs, between 11 and $32 \%$ of patients make an 'essential' mistake in their inhalation technique ${ }^{6,38}$ - an 'essential' mistake being defined as one that may drastically reduce or even prevent the deposition of a drug in the lungs. Examples are: lack of inhalation through the mouthpiece; not rotating the basal grip of the Turbuhaler (in the upright position) before inhalation; blowing in the device before inhalation (which may cause valvular dysfunction); or inhaling too fast while pressing the canister of the pMDI. ${ }^{38}$ Two other studies failed to demonstrate clear differences in inhaler technique due to age (20-81 yr), or education. ${ }^{7,13}$

\section{Teaching the use of inhalers}

There are many available DPI inhaler devices all with particular 
instructions for use. Consequently, health professionals should be instructed and trained in the use of each individual device before they can educate patients. The preparation and manipulation for loading each different device, as well as the general maintenance required, should be provided in the form of clear instructions for patients ${ }^{39}$ (see Table 5). In one study, (verbal) group instruction seemed to be more effective than personal or video instruction, ${ }^{40}$ whereas in another study written instruction alone was inadequate. ${ }^{11}$

\section{Tailoring the device to patients' needs, preferences and ability}

Since the inhaler technique required for different types of device is so different, it seems sensible to prescribe a single type of device for different drugs for individual patients. ${ }^{8,41}$ However, this is not always possible, and so different drug/delivery device combinations are prescribed; therefore, it is important to ensure the patient can use them. Unfortunately, lack of knowledge amongst health professionals is one of the major obstacles to the effective training of patients in inhaler technique. ${ }^{42-44}$

Important factors to consider when selecting an inhaler include the patient's preference and their ability to use and generate an appropriate level of inspiratory flow for the preferred device. For patients with spontaneous breathing, good co-ordination and poor inspiratory flow (e.g. patients with severe airways obstruction), a pMDI may be the first choice. For patients with inadequate co-ordination but with sufficient inspiratory flow of $>30 \mathrm{~L} / \mathrm{min}$ (e.g. children $>4$ years of age, some elderly patients), a DPI, pMDI + spacer, or a breath-actuated pMDI are all possible choices. Where necessary, pMDI inhaler aids like the Haleraid may assist patients in actuating the device. For patients who are unable to co-ordinate actuation and inhalation and/or generate insufficient inspiratory flow, the combination of a pMDI with a spacer is the obvious choice. While not included in this review, a nebuliser could be used as an adequate alternative to a pMDI + spacer) and a DPI, where appropriate, especially in the acute setting. ${ }^{24,25}$ However, nebulisers are not recommended for regular treatment because they are more expensive, time-consuming to use and require appropriate maintenance. Furthermore, there is evidence that a larger systemically absorbed dose is administered by nebulisers. ${ }^{10}$

The physician's knowledge of devices combined with the patient's preferences influence prescribing. ${ }^{18}$ In order to facilitate the choice of drug/device combinations for an individual patient, we have summarised some useful questions in Table 6.

\section{Inhalation technique follow-up}

An asthma or COPD clinical review should allow sufficient

\section{Table 6. Questions for the selection of inhalation}

devices $(*)$.

Which devices are available that deliver the desired drug?

Can the same type of device be used for all inhaled

drugs prescribed for the patient?

Which device does the patient prefer to use?

Is the patient capable of reproducing the correct handling

and inhalation manoeuvre required?

Which are the most convenient and portable for each

clinical situation?

With which devices is the physician familiar?

(*) Modified from ref. 48

time for checking and instructing patients on their inhaler technique. This should be repeated regularly in follow-up visits, since patients tend to forget the appropriate inhaler technique and sometimes introduce new errors with time. ${ }^{45,46}$ Recently, GINA and GOLD have published updated treatment guidelines focused on achieving asthma control ${ }^{24}$ and improving the prevention and management of COPD. ${ }^{25}$ If control is maintained for at least three months it would be appropriate to consider stepping down inhaled treatment gradually. Conversely, if asthma is not controlled or symptoms are increased in the COPD patient, it may not be appropriate to step up the treatment immediately; it would first be wise to consider the presence of aggravating (trigger) factors, poor adherence to medical advice, and inefficient inhaler technique. Inhaler technique should be checked routinely and where appropriate patients need to be taught, and have their inhaler technique corrected and checked regularly, during follow-up. If the patient is unable to use a particular inhaler type despite repeated attempts, a different device type should be tried until successful. It should be remembered that the most expensive inhaler device is the one that a patient cannot use...

In cases where ongoing uncontrolled asthma or increased symptoms of COPD persist in the face of correct inhaler technique, then and only then should treatment be stepped up.

\section{Conclusion}

Inhalation therapy is one of the cornerstones of treatment for asthma and COPD, in that the drug is delivered directly to the target organ with higher efficacy and reduced risk of side effects. Poor inhalation technique results in less drug deposition in the lung with reduced therapeutic effects. Delivery system properties, the patient's ability to use a device properly, the patient's personal preference, and the knowledge and skill of the physician, should be considered when prescribing inhalation therapy in order to achieve the 
optimal clinical effect. In this paper we have presented basic information and inhalation instructions concerning the most commonly used inhalers, have described some ways of overcoming difficulties encountered, and have also provided several hints for clinicians to aid their selection of an appropriate device for the treatment of their respiratory patients. Finally, with so many possible factors that could influence patient use and compliance with inhaled therapy, we have emphasised the essential need to check and re-check patients' inhaler technique at every opportunity.

\section{Addendum}

\section{The ADMIT Working Group}

ADMIT is a consortium of European respiratory clinicians with special expertise in inhalation therapy who review published evidence to examine ways of improving the treatment of obstructive pulmonary airway diseases in Europe. ADMIT is supported by an unrestricted educational grant from MEDA AB. Members of ADMIT receive a small honorarium from MEDA $A B$ for attending meetings, and travel expenses are reimbursed. See the first ADMIT paper published in this journal in December 2007 for a full list of individual conflict of interest declarations. ${ }^{4}$

\section{Conflict of interest declaration}

Mark Levy is the Editor-in-Chief of the $P C R J$, but was not involved in the editorial review of, nor the decision to publish, this article.

\section{Affiliations:}

Peter J Barnes. National Heart and Lung Institute, Imperial College, London, UK. Mariëlle Broeders. Radboud University Medical Centre, Nijmegen, Netherlands, Chris Corrigan. Department of Asthma, Allergy and Respiratory Science, King's College London School of Medicine, London, UK

Graham K Crompton. Western General Hospital, Edinburgh, Scotland, UK Lorenzo Corbetta. Università degli Studi di Firenze, Unità Funzionale di Medicina Respiratoria, Italy

Richard Dekhuijzen. Radboud University Medical Centre, Nijmegen, Netherlands, Jean Christophe Dubus. Unité de Medicine Infantile, Marseille, France

Thomas Hausen. General Practice, Grafenstrasse 62, Essen, Germany

Meinhard KneußI. Wilhelminenspital, Vienna, Austria

Federico Lavorini. Università degli Studi di Firenze Unită Funzionale di Medicina Respiratoria, Italy

Mark L Levy. University of Edinburgh, Division of Community Health Sciences: GP Section, Edinburgh, Scotland, UK

Søren Pedersen. Paediatric Research Unit, Kolding Hospital, University of Southern Denmark, Denmark.

Antonio Ramalho de Almeida. Pr. General Humberto Delgado 267, Porto, Portugal

Joaquin Sanchis. Departament de Pneumologia, Hospital de la Santa Creu i Sant Pau, Universitat Autónoma de Barcelona, Barcelona, Spain

Jose L. Viejo. Hospital General Yagüe de Burgos, Spain

Walter Vincken. Academisch Ziekenhuis VUB, Dienst Pneumologie, Brussels, Belgium

Thomas Voshaar. Krankenhaus Bethanien, Moers, Germany

\section{References}

1. Larsson S, Svedmyr N. Bronchodilating effect and side effects of Beta 2 -adrenoceptor stimulants by differen modes of administration (tablets, Metered Aerosol, and combinations thereof). Am Rev Respir Dis 1977;116: 861-9.

2. Toogood JH, Baskerville J, Jennings B, Lefcoe NM, Johansson JA. Bioequivalent doses of budesnide and prednisone in moderate and severe asthma. J Allergy Clin Immunol 1989;84:688-700. http://dx.doi.org/10.1016/0091-6749(89) 90297-2

3. Lipworth BJ. Systemic adverse effects of inhaled corticosteroid therapy. A systematic review and meta-analysis. Arch Intern Med 1999;159:941-55. http://dx.doi.org/10.1001/archinte.159.9.941

4. Dekhuijzen PN, Magnan A, Kneussl M on behalf of the ADMIT Working Group. The ADMIT series - issues in inhalation therapy. 1) The goals of asthma treatment: can they be achieved? Prim Care Resp J 2007;16(6):341-8. http://dx.doi.org/10.3132/pcrj.2007.00081

5. Cochrane MG, Bala MV, Downs KE, Mauskopf J and Ben-Joseph RH. Inhaled corticosteroids for asthma therapy. Patient compliance, devices and inhalation technique. Chest 2000;117:542-50. http://dx.doi.org/10.1378/ chest.117.2.542

6. Hesselink AE, Penninx BW, Wijnhoven HA, Kriegsman DM, van Eijk JT. Determinants of an incorrect inhalation technique in patients with asthma or COPD. Scand J Prim Health Care 2001;19:255-60. http://dx.doi.org/10.1080/ 02813430152706792

7. van Beerendonk I, Mesters I, Mudde AN, Tan TD. Assessment of the inhalation technique in outpatients with asthma or chronic obstructive pulmonary disease using a metered-dose inhaler or dry powder device. J Asthma 1998;35:273-9. http://dx.doi.org/10.3109/02770909809068218

8. Newman SP. Inhaler treatment options in COPD. Eur Respir Rev 2005;14:10208.

9. Brocklebank D, Ram F, Wright J et al. Comparison of the effectiveness of inhaler devices in asthma and chronic obstructive airway disease: a systematic review of the literature. Health Technol Assess 2001;5:1-149.

10. Dolovich MB, Ahrens RC, Hess DR, et al. Device selection and outcomes of aerosol therapy: Evidence-based Guidelines. ACCP/ACAAI. Chest 2005;127: 335-71. http://dx.doi.org/10.1378/chest.127.1.335

11. Crompton GK. Problems patients have using pressurised aerosol inhalers. Eur J Respir Dis 1982;63(Suppl 119):101-04.

12. Chen SH, Yin TJ, Huang JL. An exploration of the skills needed for inhalation therapy in schoolchildren with asthma in Taiwan. Ann Allergy Asthma Immunol 2002;89:311-15.

13. Giraud V, Roche N. Misuse of corticosteroid mertered-dose inhaler is associated with decreased asthma stability. Eur Respir J 2002;19:246-51. http://dx.doi.org/10.1183/09031936.02.00218402

14. Gabrio BJ, Stein SW, Velasquez DJ. A new method to evaluate plume characteristics of hydrofluoroalkane and chlorofluorocarbon metered dose inhalers. Int J Pherm 1999;186(1):3-12. http://dx.doi.org/10.1016/S03785173(99)00133-7

15. Orehek J, Gayrard P, Grimaud Ch, Charpin J. Patient error in use of bronchodilator metered aerosols. BMJ 1976;1:76. doi:10.1136/bmj.1.6001.76

16. Paterson IC, Crompton GK Use of pressurised aerosols by asthmatic patients. BMJ 1976;1:76-77. http://dx.doi.org/10.1136/bmj.1.6001.76-a

17. Gayrard P, Orehek L. Mauvaise utilisation des aérosols-doseurs par les asthmatiques. Respiration 1980;40:47-52. http://dx.doi.org/10.1159/ 000194250

18. Lenney J, Innes JA, Crompton GK. Inappropriate inhaler use: assessment of use and patient preference of seven inhalation devices. Respir Med 2000;94:496500. http://dx.doi.org/0.1053/rmed.1999.0767

19. Melchor R, Biddiscombe MF, Mak VHF, Spiro SG. Lung deposition patterns of directly labelled salbutamol in normal subjects and in patients with reversible airflow obstruction. Thorax 1993;48:506-11. http://dx.doi.org/10.1136/ thx.48.5.506

20. Lipworth Bj. New perspectives on inhaled drug delivery and systemic bioactivity. Thorax 1995;50:105-10. http://dx.doi.org/10.1136/thx.50.2.105

21. Barry PW, O'Callaghan C. In vitro comparison of the amount of salbutamol available for inhalation from different formulations used with different spacer devices. Eur Respir J 1997;10:1345-8. http://dx.doi.org/10.1183/ 09031936.97.10061345

22. Mitchell JP, Nagel MW. Valved holding chambers (VHCs) for use with pressurised metered-dose inhalers ( $p M D I s)$ : a review of causes of inconsistent medication delivery. Prim Care Resp J 2007;16:207-214. 
MEAC Broeders et al.

http://dx.doi.org/10.3132/ pcrj.2007.00034

23. Fink JB. Metered-dose inhalers, dry powder inhalers, and transitions. Respir Care 2000;45:623-35.

24. The Global Initiative on Asthma Global Strategy for Asthma Management and Prevention NHLBI/WHO Workshop Report. 2006 update. Available from : http://www. ginasthma.com

25. Global Initiative for chronic obstructive lung disease. Global strategy for the diagnosis, management, and prevention of chronic obstructive pulmonary disease. Updated 2005 (Based on an April 1998 NHLBI/WHO Workshop).

26. Newman SP, Weisz AW, Talaee N, Clarke SW. Improvement of drug delivery with a breath actuated pressurised aerosol for patients with poor inhaler technique. Thorax 1991;46:712-16. http://dx.doi.org/10.1136/thx.46.10.712

27. Fergusson RJ, Lenney J, McHardy GJR, Crompton GK. The use of a new breathactuated inhaler by patients with severe airflow obstruction. Eur Respir J 1991; 4:172-4.

28. Donnell D. Inhaler corticosteroid delivery systems: clinical role of a breathactuated device. Eur Rev Med Pharmacol Sci 2001;5:7-16.

29. Bell JH, Hartley PS, Cox JS. Dry powder aerosols. I. A new powder inhalation device. J Pharm Sci 1971;60:1559-64. http://dx.doi.org/10.1002/ jps.2600601028

30. Hallworth GW. An improved design of powder inhaler. Br J Clin Pharmacol 1977;4:689-90.

31. Wetterlin K. Turbuhaler: A new powder inhaler for administration of drugs to the airways. Pharm Res 1988;5:506-08. http://dx.doi.org/10.1023/ A:1015969324799

32. Pover GM, Langdon CG, Jones SR, Fidler C. Evaluation of a Breath Operated Powder Inhaler. J Int Med Res 1988;16:201-03.

33. Brindley A, Sumby BS, Smith IS, Prime D, Haywood PA, Grant AC. Design, manufacture and dose consistency of Serevent Diskus inhaler. Pharm Tech Eur 1995; 7:14-22.

34. Borgstrom L, Bondesson E, Morén F, Trofast E, Newman SP. Lung deposition of budesonide inhaled via Turbuhaler: a comparison with terbutaline sulphate in normal subjects. Eur Respir J 1994;7:69-73. http://dx.doi.org/10.1183/ 09031936. 94.07010069

35. Frijlink HW, De Boer AH. Dry powder inhalers for pulmonary drug delivery. Expert Opin Drug Deliv 2004;1:67-86. http://dx.doi.org/ 10.1517/17425247.1.1.67

36. Brown PH, Ning AC, Greening AP, McLean A, Crompton GK. Peak inspiratory flow through Turbuhaler in acute asthma. Eur Respir J 1995;8(11):1940-1. http://dx.doi.org/10.1183/09031936.95.08111940

37. Meakin BJ, Cainey J, Woodcock PM. Effect of exposure to humidity on terbutaline delivery from Turbuhaler dry powder inhalation devices. (Letter). Eur Respir J 1993;6:760-1

38. Molimard M, Raherison C, Lignot S, Depont F, Abouelfath A, Moore N. Assessment of handling of inhaler devices in real life: an observational study in 3811 patients in primary care. J Aerosol Med 2003;16:249-54. http://dx.doi.org/10.1089/089426803769017613

39. Chapman KR, Voshaar TH, Virchow JC. Inhaler choice in primary care. Eur Respir Rev 2005;14:117-22. http://dx.doi.org/10.1183/09059180. 05.00009607

40. van der Palen J, Klein JJ, Kerkhoff AH, van Herwaarden CL, Seydel ER. Evaluation of the long-term effectiveness of three instruction modes for inhaling medicines. Patient Educ Couns 1997;32(1 Suppl):S87-95. http://dx.doi.org/10.1016/S0738-3991(97)00100-6

41. van der Palen J, Klein JJ, van Herwaarden CL, Zielhuis GA, Seydel ER. Multiple inhalers confuse asthma patients. Eur Respir J 1999;14:1034-7. http://dx.doi.org/10.1183/ 09031936.99.14510349

42. Kesten S, Zive K, Chapman KR. Pharmacist knowledge and ability to use inhaled medication delivery systems. Chest 1993;104:1737-42. http://dx.doi.org/10.1378/ chest.104.6.1737

43. Hanania NA, Wittman R, Kesten S, Chapman KR. Medical personnel's knowledge of and ability to use inhaling devices. Metered-dose inhalers, spacing chambers, and breath-actuated dry powder inhalers. Chest 1994;105:111-16. http://dx.doi.org/10.1378/chest.105.1.111

44. Plaza V, Sanchis $\int$ Medical personnel and patient skill in the use of metered does inhalers. a multicentre study. CESEA Group. Respiration 1998;6:195-8. http://dx.doi.org/10.1159/000029259

45. Darr MS, Self TH, Ryan MR, Vanderbush RE, Boswell RL. Content and retention evaluation of an audiovisual patient-education program on bronchodilators. Am J Hosp Pharm 1981;38:672-5.

46. Kesten S, Elias M, Cartier A, Chapman KR. Patient handling of a multidose dry powder inhalation device for albuterol. Chest 1994;105:1077-81. http://dx.doi.org/10.1378/chest.105.4.1077

47. Newman SP, Clarke SW. Inhalation devices and techniques, in: Clark TJH, Godfrey S and Lee TH, 3rd Ed. London: Chapman \& Hall Medical 1992, p.469505

48. Geller DE. Comparing clinical features of the nebulizer, metered-dose inhaler, and dry powder inhaler. Respir Care 2005;50:1313-21.

Available online at http://www.thepcrj.org 